\title{
Inequalities: the "gap" remains; can surveillance aid in closing the gap?
}

\author{
Stefano Campostrini · David V. McQueen
}

Received: 22 January 2014/ Accepted: 27 January 2014/Published online: 13 February 2014

(C) Swiss School of Public Health 2014

Three years have passed since this Journal had an editorial on the surveillance of social determinants of health (SDOH, Campostrini et al. 2011), and during those years considerable literature, some ten articles alone last year in this journal, as well as several important events, documents (EC 2013) and conferences have stressed the importance of the subject. Among these salient events was the so-called Rio Declaration on Social Determinants of Health (http:// www.who.int/sdhconference/declaration/en/). Although without using the word surveillance (preferring monitormonitoring), this Declaration clearly pointed out the importance for countries to observe the health effects of the $\mathrm{SDOH}$ and to monitor progresses in improving the impact of these leading causes of NCDs. In addition, the Global Action Plan approved by the 66th World Health Assembly (http://www.who.int/nmh/events/ncd_action_plan/en/ index.html) considers it strategic to address the SDOH (named 14 times in the document) and the necessary surveillance (named 24 times). Many articles have added more and more evidence to the findings of the earlier WHO report (CSDH 2008): SDOH affects health outcomes globally, nationally, locally. Among the few attempts to measure how the effect of SDOH was evolving in recent years showed that actually things are not always going for the better (WHO-Europe 2013), and health inequality is increasing globally as well as in most countries (see for instance EC 2013): most inequality indicators between

S. Campostrini $(\square)$

Department of Economics, University Ca' Foscari of Venice,

San Giobbe 873, 30121 Venice, Italy

e-mail: stefano.campostrini@unive.it

D. V. McQueen

2418 Midvale Court, Tucker, GA 30084, USA

e-mail: davidmcqueen07@gmail.com countries are decreasing, but some, e.g., the Gini index applied to life expectancy for males has increased $4 \%$ in the last decade; and when inequality is considered between regions within the Member States, many countries-more than half-show an increase in regional inequalities (EC 2013, p 34).

This cumulative evidence of the effects of the SDOH on health raises a major question: do we really need more evidence that shows SDOH effects? Or, perhaps, do we need something else? Perhaps we do not need to give a definitive answer to this question, but rather to present some reflections and perhaps provoke a discussion. These reflections are based on our own years, now decades, of involvement with the surveillance of risk factors for NCDs (see, e.g., McQueen and Puska 2003; Campostrini and McQueen 2005; Campostrini 2013).

1. It remains critical to (continuously) monitor the SDOH and more importantly to understand the mechanisms by which the SDOH operate in producing health disparities/inequities.

We still see this as a challenge for several reasons. First, causality is always difficult to ascertain. Second, our existent surveillance systems quite seldom apply "sophisticated" analyses to help detect underlying causal properties. Critically, we have relied on simplistic measures of the social determinants that give descriptive findings but lack insight into the causal mechanisms of the social determinants.

2. We need "good" surveillance systems (Campostrini 2013) and ability to measure several SDOH variables or at least the capability to link information on health outcomes to the causes (risk factors) and to the measures of the "causes of the causes", the SDOH 
(social and cultural capital, urban settings, to name a few, beside the classical income and education).

3. We need significant resource investment on data collection and a profound emphasis on in depth analysis on SDOH.

4. Research should go beyond mere description of SDOH and health inequalities and explore why and how social factors operate in producing health inequalities to understand how changes can be made to address the public health implications of the SDOH.

In sum, we need to now focus on data collection and analyses that address the problems invoked by the social determinants of health and how they lead to inequities in health at a population level (some works going in this direction have been already published in this Journal, see, for instance, Spiegel et al. 2012; Salonna et al. 2012; Klein et al. 2012). This is the public health challenge. Some of these points are reflected in the recently published Marmot's report for the EC (2013): beside a clear presentation of the situation and what has been done so far in Europe, it emerges quite clearly the need "to do something, do more, do better" already presented in the Marmot's commission report for WHO (CSDH 2008) and explicitly in the recommendations for the EU Member States, where it is pointed out the need for more capacities for coherent and effective implementation (recommendation \#3) and for a progressive improvement in availability and use of data to plan, monitor and evaluate actions (recommendation \#5).

In this new decade, with all the targets set (at different levels) for the health of 2020, there should be a shift, certainly at the policy level, but also at the research one, in trying to find evidence for what really works to "close the gap". Certainly in this, a necessary condition will be the availability of good surveillance systems capable of offering information to show the evidence of "what works" in closing the gap (WARFS 2011).

\section{References}

Campostrini S (2013) Surveillance for NCDs and health promotion: an issue of theory and method. In: McQueen DV (ed) Global handbook on noncommunicable diseases and health promotion. Springer, New York, pp 51-70

Campostrini S, McQueen DV (2005) Institutionalization of social and behavioral risk factor surveillance as a learning system. Int $\mathbf{J}$ Health Promotion 50:s9-s15

Campostrini S, McQueen DV, Abel T (2011) Social determinants and surveillance in the new Millennium. Int $J$ Public Health $56: 357-358$

CSDH (2008) Closing the gap in a generation: health equity through action on the social determinants of health. Final report of the commission on social determinants of health, World Health Organization, Geneva

EC (2013) Health inequalities in the EU-final report of a consortium. Consortium lead: Sir Michael Marmot, European Commission Directorate-General for Health and Consumers, EU

Klein J, Vonneilich N, Baumeister SE, Kohlmann T, von dem Knesebeck O (2012) Do social relations explain health inequalities? Evidence from a longitudinal survey in a changing eastern German region. Int J Public Health 57:619-627

McQueen DV, Puska P (eds) (2003) Global Behavioral Risk Factor Surveillance. Kluwer Academic/Plenum Publishers, New York

Salonna F, Madarasova Geckova A, Zezula I, Slekova M, Groothoff JW, Reijneveld SA, van Dijk JP (2012) Does social support mediate or moderate socioeconomic differences in self-related health among adolescents? Int J Public Health 57:609-617

Spiegel J, Alegret M, Clair V, Pagliccia N, Martinez B, Bonet M, Yassi A (2012) Intersectoral action for health at a municipal level in Cuba. Int J Public Health 57:15-23

WARFS (2011) The World Alliance for Risk Factor Surveillance White Paper on Surveillance, International Union for Health Promotion and Education, Paris. http://www.iuhpe.org/images/ GWG/WARFS/WARFS_white_paper_draft_may_2011.pdf

WHO Europe (2013) World Health Organization Regional Office for Europe. Review of social determinants and the health divide in the WHO European Region: final report. 30 Oct 2013, at: http:// www.euro.who.int/en/publications/abstracts/review-of-socialdeterminants-and-the-health-divide-in-the-who-european-region.final-report 